\title{
ACCRETION AND PRESERVATION OF D-RICH ORGANIC PARTICLES IN CARBONACEOUS CHONDRITES: EVIDENCE FOR IMPORTANT TRANSPORT IN THE EARLY SOLAR SYSTEM NEBULA
}

\author{
L. Remusat ${ }^{1}$, Y. GuAn, Y. Wang, AND J. M. EILER \\ Geological and Planetary Sciences Division, California Institute of Technology, 1200 E. California Blvd, Pasadena, CA 91125, USA \\ Received 2009 November 11; accepted 2010 March 2; published 2010 March 30
}

\begin{abstract}
We have acquired NanoSIMS images of the matrices of CI, CM, and CR carbonaceous chondrites to study, in situ, the organic matter trapped during the formation of their parent bodies. $\mathrm{D} / \mathrm{H}$ ratio images reveal the occurrence of D-rich hot spots, constituting isolated organic particles. Not all the organic particles are D-rich hot spots, indicating that at least two kinds of organic particles have been accreted in the parent bodies. Ratio profiles through D-rich hot spots indicate that no significant self-diffusion of deuterium occurs between the D-rich organic matter and the depleted hydrous minerals that are surrounding them. This is not the result of a physical shielding by any constituent of the chondrites. Ab initio calculations indicate that it cannot be explained by isotopic equilibrium. Then it appears that the organic matter that is extremely enriched in D does not exchange with the hydrous minerals, or this exchange is so slow that it is not significant over the 4.5 billion year history on the parent body. If we consider that the D-rich hot spots are the result of an exposure to intense irradiation, then it appears that carbonaceous chondrites accreted organic particles that have been brought to different regions of the solar nebula. This is likely the result of important radial and vertical transport in the early solar system.
\end{abstract}

Key words: astrochemistry - meteorites, meteors, meteoroids - protoplanetary disks

\section{INTRODUCTION}

Carbonaceous chondrites are the most primitive known meteorites and likely formed 4.56 billion years ago. The elemental bulk compositions of these meteorites resemble the Sun for all but the most volatile elements (Anders \& Grevesse 1989; Lodders 2003). Their parent bodies accreted from several discrete components of the early solar system: calcium-aluminum-rich inclusions (CAIs; refractory inclusions inferred to be the first condensates from the solar nebula), other silicates, ice, organics, and adsorbed noble gases (Scott \& Krot 2003). The carbonaceous chondrites are inferred to come from small (tens of kilometer) parent bodies that did not undergo differentiation by partial melting. Nevertheless, radioactive decay of short live radionucleides heated these parent bodies soon after their accretion, driving variable amounts of thermal metamorphism (Huss et al. 2006) and aqueous alteration (Krot et al. 2006). Despite this post-accretionary modification, at least some components of the organic matter in the carbonaceous chondrites retained distinctive isotopic and molecular properties that plausibly relate to their pre-accretionary origins in the early solar nebula or in the molecular cloud that gave birth to it (Alexander et al. 2007; Kerridge 1983; Pizzarello et al. 2006; Remusat et al. 2006; Robert \& Epstein 1982). The processes that gave rise to early solar system organic matter and the extents to which they were modified by parent-body processes are still a matter of debate.

The organics in carbonaceous chondrites include components that are characterized by distinctive deuterium enrichment (i.e., relative to terrestrial organic matter and other material in the meteorites; Epstein et al. 1987; Pizzarello et al. 2006; Yang \& Epstein 1983). The origin of this D-enrichment is enigmatic, and it is unclear how strongly it has been influenced by postaccretionary metamorphism and aqueous-alteration. Alexander et al. (2007) have argued that variations of the $\mathrm{D} / \mathrm{H}$ ratio of insoluble organic matter (IOM), particularly differences between

\footnotetext{
1 Present address: CNRS - Museum National d'Histoire Naturelle, Laboratoire de Minéralogie et Cosmochimie du Museum - UMR 7202, Case 52, 57 rue Cuvier, 75231 Paris Cedex 05, France.
}

classes of chondrites, might result from alteration of a common, relatively homogeneous precursor by parent-body processes. Indeed, among carbonaceous chondrites, $\mathrm{CR}$ - expected to be the least altered or metamorphosed-have the highest $\mathrm{D} / \mathrm{H}$ ratio, whereas $\mathrm{CI}$ and $\mathrm{CM}$ (more hydrated) have a lower one, and $\mathrm{CO}$ and $\mathrm{CV}$ (thermally metamorphosed) have the lowest $\mathrm{D} / \mathrm{H}$ of carbonaceous chondrites. Differences in the molecular structure of IOM between different classes of carbonaceous chondrites have been interpreted as consequences of parent-body heating and/or aqueous reactions. In particular, heating processes increase ordering and size of aromatic units and loss of the most labile constituents (Bonal et al. 2007; Bonal et al. 2006; Cody et al. 2008; Remusat et al. 2008; Sephton et al. 2003), whereas hydrothermal alteration oxidizes IOM, adding hydroxyl groups and lowering the aliphatic component (Cody \& Alexander 2005; Remusat et al. 2005; Yabuta et al. 2005). Nevertheless, very high $\mathrm{D} / \mathrm{H}$ ratios in ordinary chondrites relative to other groups that appear to have undergone similar heating (CO and $\mathrm{CV}$ ) are difficult to understand in the context of this interpretation of the origins of diversity among IOM components in chondritic meteorites (Alexander et al. 2007).

The recent discovery of extraordinary D enrichments in micron-scale domains of organic matter from carbonaceous chondrites (Busemann et al. 2006) reveals that isotopic variations among IOM, whatever their origin, extend down to scales characteristic of individual mineral grains in the matrices of chondritic meteorites, and it has long been recognized that organic matter in carbonaceous chondrites is far from hydrogenisotope equilibrium with D-poor water and hydroxyl groups in hydrous silicates in co-existing matrix (Robert \& Epstein 1982). These observations suggest that parent-body processes, whatever their influence on IOM might be, have not led to isotopic homogenization and exchange over scales of multiple microns. Similarly, organic radicals are found in the IOM of Murchison, Orgueil, and Tagish Lake (Binet et al. 2002). Such moieties are destroyed by contact with hot water, suggesting that hydrothermal alteration on the parent body may have had limited effect on the molecular structure of the IOM. However, as no one 
has succeeded at measuring these organic radicals in situ, it is imaginable that they are preserved in armored locations within the matrix (e.g., as inclusions within anhydrous minerals) that thus avoided parent-body alteration that pervaded most of the matrix. Measurements of the $\mathrm{D} / \mathrm{H}$ ratios of radicals in IOM from Orgueil using pulsed electron paramagnetic resonance (Gourier et al. 2008) reveal that these moieties are the most D-enriched natural materials in the solar system $(\mathrm{D} / \mathrm{H}=1.5 \% \pm 0.5 \%)$. It has been suggested that these radicals are the origin of D-rich micron-scale domains in Orgueil IOM (Remusat et al. 2009). If so, one might infer the locations of radical-rich locations in IOM or the chondritic matrix material by mapping the distribution of D in those materials (Binet et al. 2002; Remusat et al. 2009).

We used a NanoSIMS ion microprobe to create ion images of D-enriched organic particles in situ within fragments of the matrices of Orgueil (CI1), Tagish Lake (CI2 ?), Murchison (CM2), Cold Bokkeveld (CM2), and Renazzo (CR2). While previous studies of this kind have demonstrated the existence of spatially resolved and highly D-rich domains (hereafter called D-rich hot spots) within separates of IOM (Busemann et al. 2006; Nakamura-Messenger et al. 2006; Remusat et al. 2009), this is the first such study to examine the textural relationships between organic D-rich (and presumably radical rich) hot spots and inorganic material. Such textural information, combined with secondary-electron microscopy (SEM) imaging before and after ion imaging, has permitted us to assess the specific processes involved in the preservation of D-enriched compounds in hydrated carbonaceous chondrites.

\section{EXPERIMENTAL}

\subsection{Sample Preparation}

The sample of Orgueil examined in this study was provided by the Museum National d'Histoire Naturelle, Paris, France. Samples of Murchison, Cold Bokkeveld, and Renazzo were provided by François Robert (Laboratoire de Mineralogie et Cosmochimie du Museum, MNHN, Paris). A sample of Tagish Lake was provided by Mike Zolensky (JSC, Houston). We isolated small fragments (less than $0.5 \mathrm{~mm}$ ) of matrix material (i.e., excluding large chondrules, CAI's, or other minerals) of interior parts of bulk samples from each meteorite and pressed them into clean (surface wiped with alcohol before pressing the samples) indium foil without any chemical treatment. We focus on matrix samples because it has been shown previously that organic matter in the carbonaceous chondrites is concentrated within the matrix (Pearson et al. 2002). All samples were then gold coated (30 $\mathrm{nm}$ thick) prior to NanoSIMS and SEM observations.

\subsection{NanoSIMS Settings}

All ion microprobe analyses described in this study were made using the NanoSIMS 50L located at the Caltech Microanalysis Center. A focused $\mathrm{Cs}^{+}$primary beam was used to raster areas of $10 \times 10,20 \times 20$, or $40 \times 40 \mu \mathrm{m}^{2}$ while collecting $\mathrm{H}^{-}, \mathrm{D}^{-},{ }^{12} \mathrm{C}^{-},{ }^{18} \mathrm{O}^{-},{ }^{26} \mathrm{CN}^{-},{ }^{28} \mathrm{Si}^{-}$, and ${ }^{32} \mathrm{~S}^{-}$ions. Analyses were made in "combined analysis mode"; i.e., with magnetic peak switching between two different B-fields; this was done to facilitate measurements that spanned a large range in masses of collected ions (a factor of 34), so we could interrogate both the composition (elemental and isotopic) of organic matter and the textural relationships of organic matter to adjacent inorganic material rich in $\mathrm{O}, \mathrm{Si}$, and $\mathrm{S}$. Only $\mathrm{D} / \mathrm{H}$ isotopic ratios will be discussed in this paper; elemental compositions will be the matter of a following paper. Mass resolution varied with tuning condition from session to session, but in all cases was sufficient to cleanly resolve ${ }^{12} \mathrm{C}^{14} \mathrm{~N}$ - from ${ }^{12} \mathrm{C}_{2} \mathrm{H}_{2}$ (MRP $>6000$ ). Measurements were made during three different sessions (i.e., sets of one or more analyses made over $\sim 7$ days with a single set of instrument conditions) over a period of one year. The primary beam current varied between 2 and $4 \mathrm{pA}$ among all sessions. A focused electron beam was used to compensate the charge deficit induced by $\mathrm{Cs}^{+}$bombardment and negative ion extraction (i.e., because sample conductivity is insufficient for stable analyses). Rastered analyses covering areas of $10 \times 10 \mu \mathrm{m}$ were discretized into $128 \times 128$ pixels, with a raster speed of 2 or $3 \mathrm{~ms} \mathrm{pixel}^{-1}$. Data were processed into ion images, each of which comprises several "frames" (one frame consists of the data collected during a single passage of the beam over its rastered area). Stacking of multiple frames improves the signal and thus reduces the error associated with counting statistics. Secondary ions were collected by electron multipliers with a dead time of $44 \mathrm{~ns}$. These detectors are characterized by a low noise level and a very good sensitivity allowing us to measure precisely very low ion count rates. Instrumental fractionations (i.e., differences between measured and actual elemental and isotopic abundance ratios) were corrected by assuming linear fractionations (i.e., independent of composition) equal to those determined for a standard charcoal of known composition, measured during the same session as a given unknown measurement. Analyses of "inorganic" ions $(\mathrm{O}, \mathrm{Si}$, and $\mathrm{S})$ were not corrected for instrumental fractionations are reported as raw measured ion intensity ratios; these data are used to locate phases rich in the relevant elements rather than for quantitative analysis. Prior to each measurement, a high $\mathrm{Cs}^{+}$current (between 20 and $40 \mathrm{pA}$ ) was used to presputter the surface of the sample in order to remove the gold coating and any surface contaminants and to reach sputtering steady state.

All NanoSIMS data were processed with l'image ${ }^{\circledR}$ software developed by Larry Nittler, Carnegie Institution in Washington DC, USA. This image processing included a stage of coregistration of multiple frames to account for drift in the location of the ion beam from frame to frame. Note that this procedure generally improves effective spatial resolution and counting statistics for features that persist to significant depth in the sample, but can spuriously co-register features that are not in fact contiguous. This is among the reasons why we focus on relatively large, intense, and persistent features of ion images rather than small features that appear to persist only for a few frames. The l'image ${ }^{\circledR}$ software was also used to calculate ratio images and image profiles reported in this study.

SEM images were acquired on the LEO 1550 VP FE-SEM installed at the GPS division analytical facility, Caltech. Both secondary and backscattered electrons images were acquired. EDS elemental point measurements were recorded by using an Oxford INCA Energy 300 X-ray EDS system.

\subsection{Computational Methods}

The discussion section of this paper refers to several theoretical calculations in order to interpret analytical results. The methods employed in these calculations are briefly summarized here.

\subsubsection{Estimation of Equilibrium Fractionation Factors}

$\mathrm{D} / \mathrm{H}$ exchange between two compounds can be described by the reaction

$$
\mathrm{AH}+\mathrm{BD}=\mathrm{AD}+\mathrm{BH}
$$


If this reaction is written such that only one hydrogen atom is exchanged between $A$ and $B$, the fractionation factor associated with this reaction, $\alpha_{\text {eq }}$, is equal to the equilibrium constant, $K_{\text {eq }}$, which can be expressed as the ratio of the total partition function $(Q)$ ratios between the compounds in equilibrium:

$$
\alpha_{\mathrm{eq}}=K_{\mathrm{eq}}=\frac{Q(\mathrm{AD}) / Q(\mathrm{AH})}{Q(\mathrm{BD}) / Q(\mathrm{BH})} .
$$

Following Urey (1947) and Bigeleisen \& Mayer (1947), one can approximate the total partition function ratios in the form of reduced partition function ratio, or $\beta$ factor. That is, $\alpha_{\mathrm{eq}}$ can be written as

$$
\alpha_{\mathrm{eq}}=\frac{\beta(A)}{\beta(B)},
$$

where the value of $\beta$, calculated under the Born-Oppenheimer and harmonic oscillator approximations, is

$$
\beta=\prod_{i}^{3 N-6} \frac{u_{2 i}}{u_{1 i}} \cdot \frac{\exp \left(-u_{2 i} / 2\right)}{\exp \left(-u_{1 i} / 2\right)} \cdot \frac{\left(1-\exp \left(-u_{1 i}\right)\right)}{\left(1-\exp \left(-u_{2 i}\right)\right)},
$$

where

$$
u_{i}=\frac{h v_{i}}{k_{B} T}
$$

and $3 N-6$ is the number of normal modes for nonlinear molecules, $v_{i}$ is the vibrational frequency of the $i$ th normal mode, $h$ is the Plank constant, $k_{B}$ is the Boltzmann constant, and $T$ is temperature in Kelvin. Symmetry numbers that would otherwise occur in the expression of $\beta$ are omitted here for simplicity; they cancel when one considers isotope exchange reactions involving isotopically pure molecules.

\subsubsection{Ab Initio Modeling}

Equilibrium fractionation factors $\left(\alpha_{\mathrm{eq}}\right)$ are calculated by modeling the vibrational frequencies of a given molecule at different temperatures. Vibrational frequencies of a single organic molecule were calculated using density functional theory (DFT) approaches to quantum mechanical (QM) models of bond energies, performed using Jaguar 7.0 (Greeley 1994). Calculations were carried out at the B3LYP/6-311G** level. The solvation effect of organic molecules was simulated using the Poisson-Boltzmann continuum solvation model. Computation procedures were as follows.

Starting with a best-guess molecular geometry, an optimized geometry was first calculated in the gaseous phase and then reoptimized in the aqueous phase. The convergence criterion for the DFT electronic structure calculations was $5 \times 10^{-5}$ hartree for the energy and $5 \times 10^{-6}$ hartree/Bohr for a root mean square change in the density matrix. The convergence criterion for geometry optimization was $5 \times 10^{-5}$ hartree for the energy. The Hessian matrix (matrix for second derivatives with respect to atom positions) was calculated numerically at the optimized geometry. The same Hessian was used to calculate vibrational frequencies for isotopologues. No scaling factor was applied. Using these frequencies, the $\beta$ factor was calculated (Equation (3)) with respect to $\mathrm{D}$-substitution at an individual site in aqueous environment over the range of $0^{\circ} \mathrm{C}-100^{\circ} \mathrm{C}$.

The calculation of the $\beta$ factor for water was first performed on isolated molecules, i.e., as an ideal gas, following the same method (B3LYP/6-311G**) as described above. Then, instead of simulating liquid water, we multiplied the $\beta$ factor calculated for an ideal gas $\mathrm{H}_{2} \mathrm{O}$ with the experimentally measured liquid-vapor fractionation factor (Horita \& Wesolowski 1994) at the corresponding temperature to obtain $\beta$ factors of liquid water. The value of $\alpha_{\mathrm{eq}}$ was then calculated as the ratio of $\beta$ factors between the organic molecule in the aqueous phase and liquid water.

\section{RESULTS}

\subsection{Ratio Images}

$\mathrm{C} / \mathrm{Si}$ and $\mathrm{D} / \mathrm{H}$ ion ratio images of portions of Orgueil, Murchison, and Renazzo are displayed in Figure 1. Despite differences in parent-body evolution among these meteorites, these ion images have several characteristics in common: each image contains several particles characterized by a high $\mathrm{C} / \mathrm{Si}$ ratio and a diameter around $1 \mu \mathrm{m}$. We infer these as organicrich particles - an identification that is supported by the close association of $\mathrm{H}$ and $\mathrm{C}$ in these particles (Figure 2). These organic particles are surrounded by hydrous silicates (presumably clays), which constitute the main fraction of the matrix of the CI, $\mathrm{CM}$, and CR chondrites. In all images, these organic particles are randomly distributed, as was previously observed by fluorescence microscopy in Orgueil (Alpern \& Benkheiri 1973). Some of these particles could be nanoglobules, as previously reported in carbonaceous chondrites (Garvie \& Buseck 2004; Nakamura et al. 2002), but the spatial resolution of our technique does not allow us to determine if we observed nanoglobules or not.

Some of these organic particles exhibit an extreme enrichment in $\mathrm{D}$, up to $\mathrm{D} / \mathrm{H}=3.6 \times 10^{-3}$ in Orgueil. D-rich "hot spots" (i.e., $\sim 1 \mu \mathrm{m}$ high-D/H domains) have been reported previously in IOM of CI, CM, and CR, and in bulk rocks (Busemann et al. 2006; Remusat et al. 2009). One interesting point revealed by our study is that it appears that higher $\mathrm{D} / \mathrm{H}$ ratios are observed in "hot spots" within the untreated meteorite matrix fragments than in hotspots in chemically isolated IOM (see Table 1): i.e., the maximum $\mathrm{D} / \mathrm{H}$ in bulk Orgueil is $3502( \pm 214) \times$ $10^{-6}$, whereas the maximum $\mathrm{D} / \mathrm{H}$ ratio measured in Orgueil IOM is $723( \pm 25) \times 10^{-6}$. Similarly, the maximum $\mathrm{D} / \mathrm{H}$ ratio observed in un-treated Murchison matrix is $1224( \pm 193) \times 10^{-6}$, whereas this ratio varies only up to $946( \pm 28) \times 10^{-4}$ in isolated IOM (Remusat et al. 2009). We suspect that this is because the most deuterium-rich components of organic-rich particles are dissolved or undergo isotopic exchange during the acid demineralization procedure that is commonly used to recover the IOM (this interpretation is supported by previous inferences regarding the effect of acid digestions on bulk $\mathrm{D} / \mathrm{H}$ ratios of matrix samples; Halbout et al. 1990). We cannot exclude the occurrence of soluble or hydrolysable D-rich organic matter removed during the demineralization process to isolate the IOM (up to $\mathrm{D} / \mathrm{H}=545 \times 10^{-6}$ for some amino acids in Murchison, for instance; Pizzarello et al. 1991). Despite having higher $\mathrm{D} / \mathrm{H}$ ratios, the D-rich hot spots in the bulk meteorite have the same shape as those observed in the IOM, i.e., they are circular objects having a diameter around $1 \mu \mathrm{m}$.

\subsection{Ratio Profiles}

Figure 2 reports $\mathrm{C} / \mathrm{Si}, \mathrm{H} / \mathrm{Si}, \mathrm{C} / \mathrm{H}$, and $\mathrm{D} / \mathrm{H}$ profiles through representative D-rich organic hot spots shown in Figure 1. For all the samples examined in this study, $\mathrm{C} / \mathrm{Si}$ and $\mathrm{H} / \mathrm{Si}$ profiles are indistinguishable in shape and position, indicating that in these particles $\mathrm{C}$ and $\mathrm{H}$ are intimately associated with one another and constant in their stoichiometry and/or mixing ratios at the scale of analysis ( $200 \mathrm{~nm})$. 

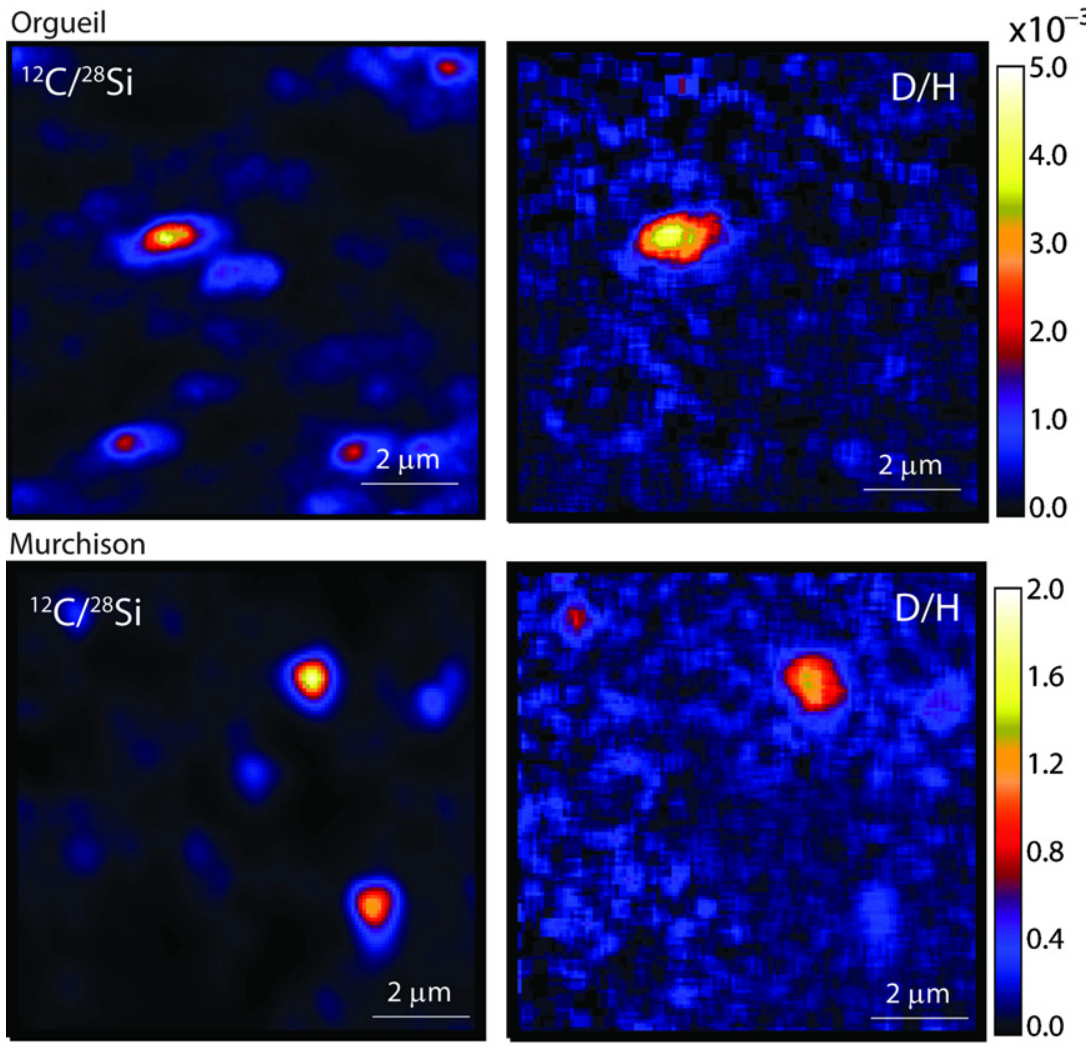

\section{Renazzo}
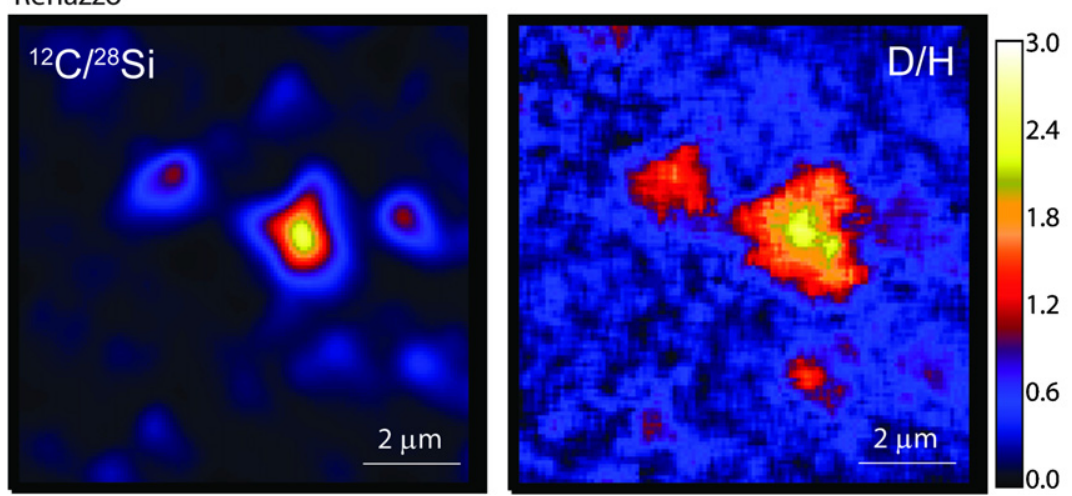

Figure 1. $10 \times 10 \mu \mathrm{m}^{2}{ }^{12} \mathrm{C} /{ }^{28} \mathrm{Si}$ and $\mathrm{D} / \mathrm{H}$ images of Orgueil, Murchison, and Renazzo. For each meteorite, the images correspond to the same area. It appears that D-rich hot spots are associated with organic particles (with high $\mathrm{C} / \mathrm{Si}$ ). Moreover, the D-rich hot spots constitute an entire organic particle, but some organic particles do not make a D-rich hot spot.

Table 1

D/H Isotopic Ratios of Organic Particles Measured in this study by NanoSIMS ${ }^{\text {a }}$

\begin{tabular}{lccccc}
\hline \hline \multicolumn{1}{c}{ Meteorite } & D/H Max & Average D/H & Analyzed Area $\left(\mu \mathrm{m}^{2}\right)$ & D/H Bulk IOM & Max D/H IOM $(\mathrm{D}-$ rich Hot Spot $)$ \\
\hline Orgueil (CI1) & $3502 \pm 214 \times 10^{-6}$ & $782 \times 10^{-6}$ & $400(21)^{\mathrm{b}}$ & $307 \times 10^{-6}(1)$ & $723 \pm 25 \times 10^{-6}(2)$ \\
Cold Bokkeveld (CM2) & $900 \pm 60 \times 10^{-6}$ & $464 \times 10^{-6}$ & $600(19)$ & $270 \times 10^{-6}(1)$ & \\
Murchison (CM2) & $1224 \pm 193 \times 10^{-6}$ & $338 \times 10^{-6}$ & $900(35)$ & $277 \times 10^{-6}(1)$ & $946 \pm 28 \times 10^{-6}(2)$ \\
Tagish Lake (C2) & $782 \pm 50 \times 10^{-6}$ & $396 \times 10^{-6}$ & $600(32)$ & $249 \times 10^{-6}(1)$ & $2695 \pm 327 \times 10^{-6}(4)$ \\
Renazzo (CR2) & $1839 \pm 49 \times 10^{-6}$ & $1167 \times 10^{-6}$ & $400(8)$ & $545 \times 10^{-6}(3)$ & 2695 \\
\hline
\end{tabular}

Notes. Data from (1) Alexander et al. 2007; (2) Remusat et al. 2009; (3) Robert \& Epstein 1982; (4) for another CR2 (other than Renazzo): EET 92042 Busemann et al. 2006. Average $\mathrm{D} / \mathrm{H}$ corresponds to the average $\mathrm{D} / \mathrm{H}$ measured in organic particles in the matrices of the studied meteorites. It may not be statistically representative of the bulk value because not enough organic particles have been measured.

${ }^{\text {a }}$ Corresponding isotopic ratios previously reported for bulk IOM and D-rich hotspots in IOM are also displayed.

$\mathrm{b}$ The number of organic particles measured.

The profiles in $\mathrm{C} / \mathrm{Si}$ and $\mathrm{H} / \mathrm{Si}$ ratio across $\mathrm{C}$-rich particles have broad, roughly Gaussian margins rather than the sharp boundaries one might anticipate if particles are uniformly $\mathrm{C}$-rich surrounded by C-poor clays, and smooth in outline. This phenomenon can be partially attributed to the $\sim 200 \mathrm{~nm}$ width of the primary ion beam used to sputter the samples. However, the length scale of observed "broadening" of these profiles $(\sim 500 \mathrm{~nm})$ is too large to be attributed to the primary beam 

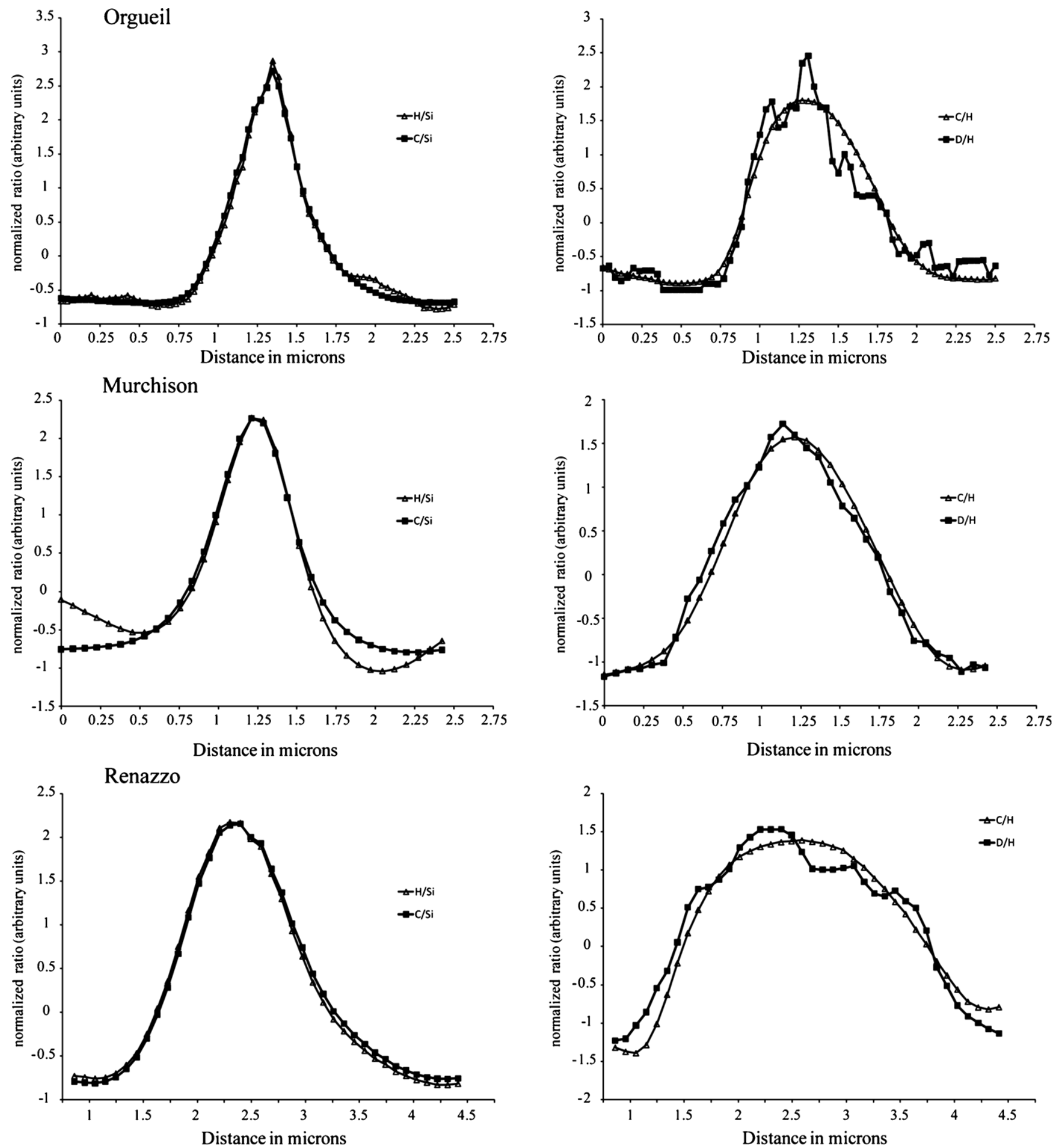

Figure 2. Ratio profiles through D-rich particles shown in Figure 1. The vertical scale represents the normalized ratio $\left(R(x)_{\text {norm }}\right)$ by using the relation $R(x)_{\text {norm }}=\frac{R(x)-\bar{R}}{\sqrt{\frac{\sum_{n}(R(x)-\bar{R})^{2}}{(n-1)}}}$, where $n$ is the number of points in the profile. These profiles indicate that in all the meteorites, $\mathrm{C}$ and $\mathrm{H}$ are associated in the $\mathrm{D}$ rich hot spots, indicating the occurrence of organic matter. Moreover, the $\mathrm{D} / \mathrm{H}$ ratio profiles do not reveal any self-diffusion of the deuterium form the organic particle to the depleted hydrous minerals, $\mathrm{C} / \mathrm{H}$ and $\mathrm{D} / \mathrm{H}$ profiles being similar.

alone. A simple explanation of this observation may be that the margins of the organic-rich particles may have irregularities that are similar to or smaller than the beam size, such that the primary beam, when placed near the edge of a C-rich particle, samples a significant amount of matrix silicate.
Because the $\mathrm{C} / \mathrm{Si}$ and $\mathrm{H} / \mathrm{Si}$ profiles across any given $\mathrm{C}$-rich particle closely resemble one another, we infer that $\mathrm{H}$ has not migrated (e.g., by diffusion) from organic particles into surrounding clays. That is, the edges of organic-rich particles retain the $\mathrm{C} / \mathrm{H}$ stoichiometry characteristic of their centers, even 
though surrounded by less H-rich materials. Though it is known that organic matter on hydrated meteorites is more oxidized than in the less hydrated meteorites (Cody \& Alexander 2005), we conclude that this oxidation was not accompanied by a net loss or dilution of hydrogen, which would have resulted in a broader $\mathrm{H} / \mathrm{Si}$ profile. Thus, alterations of the chemistry of organic-rich particles at the molecular level do not appear to be associated with net mass transport of $\mathrm{C}$ and/or $\mathrm{H}$ between those particles and immediately surrounding solids.

$\mathrm{C} / \mathrm{H}$ profiles are significantly wider and steeper-sided than $\mathrm{C} / \mathrm{Si}$ and $\mathrm{H} / \mathrm{Si}$ profiles (Figure 2). This is consistent with the chemical composition of the organic particle being relatively homogeneous. As for $\mathrm{C} / \mathrm{Si}$ and $\mathrm{H} / \mathrm{Si}$ profiles, the edges of these $\mathrm{C} / \mathrm{H}$ profiles reflect mixing between the carbon-rich organic matter and carbon-poor inorganic matrix (due to beam width and irregularities in shape), but the high concentrations of $\mathrm{C}$ and $\mathrm{H}$ within particles mean that the $\mathrm{C} / \mathrm{H}$ ratio remains dominated by organic matter even when a significant proportion of silicate is sampled. This relationship can be demonstrated through plots of $\mathrm{C} / \mathrm{Si}$ versus $\mathrm{C} / \mathrm{H}$ (not shown), which exhibit mixing hyperbola for each profile.

$\mathrm{D} / \mathrm{H}$ profiles are similar in shape and position to $\mathrm{C} / \mathrm{H}$ profiles. Note that the low secondary ion-counting rate for $\mathrm{D}$ means that each point on a $\mathrm{D} / \mathrm{H}$ profile has a relatively high analytical error, making then quite irregular over short length scales. If hydrogen inter-diffuses between the D-rich organic particles and surrounding D-poor hydrous silicates (i.e., exchanging hydrogen isotopes despite maintaining a constant $\mathrm{H}$ concentration), then the $\mathrm{D} / \mathrm{H}$ profiles would exhibit diffusion profiles wider than the edge of the $\mathrm{C} / \mathrm{H}$ profiles. This is clearly not the case, indicating that no hydrogen interdiffusion has occurred at the scales of our analyses. This is surprising for several reasons. Organic-rich particles are in intimate contact with hydrous silicates, unarmored by anhydrous phases; they have been in such contact for the age of the solar system, and early in the solar system history their parent bodies underwent aqueous alteration lasting $\sim 10^{6}$ years. And terrestrial organic matter in sedimentary rocks is known to undergo $\mathrm{H}$ isotope exchange with formation waters over geological timescales (Sessions et al. 2004). Our data require (1) hydrogen in C-rich particles is so refractory that it resisted isotopic exchange throughout their parent-body histories or (2) these particles have fully exchanged with adjacent clays or grain boundary water, but contain some component with an extraordinary reduced partition coefficient, such that it concentrated D.

\subsection{D-rich Organic Grains and the Surrounding Minerals}

We assessed whether the occurrence and preservation of D-rich hot spots were related to the identity and texture of adjacent phases by combining NanoSIMS ion images of intact matrix fragments with SEM studies before and after ion imaging. Figures 3 and 4 show the locations of two D-rich organic particles in the matrices of Orgueil and Murchison. In both cases, these organic particles are surrounded by hydrous minerals. This is consistent with previous mapping of organic compounds by Osmium labeling (Pearson et al. 2002). Post-SIMS examination of these textural associations typically revealed a "hole" where the C-rich particle was present, presumably because these particles sputter more rapidly than do adjacent hydrous silicates. Chemical compositions of hydrous minerals (determined by EDS) are consistent with previously reported compositions of Mg-rich montmorillonite-like minerals (Kerridge 1976) in Orgueil and Chlorite/Serpentinites in Murchison (Fuchs et al.

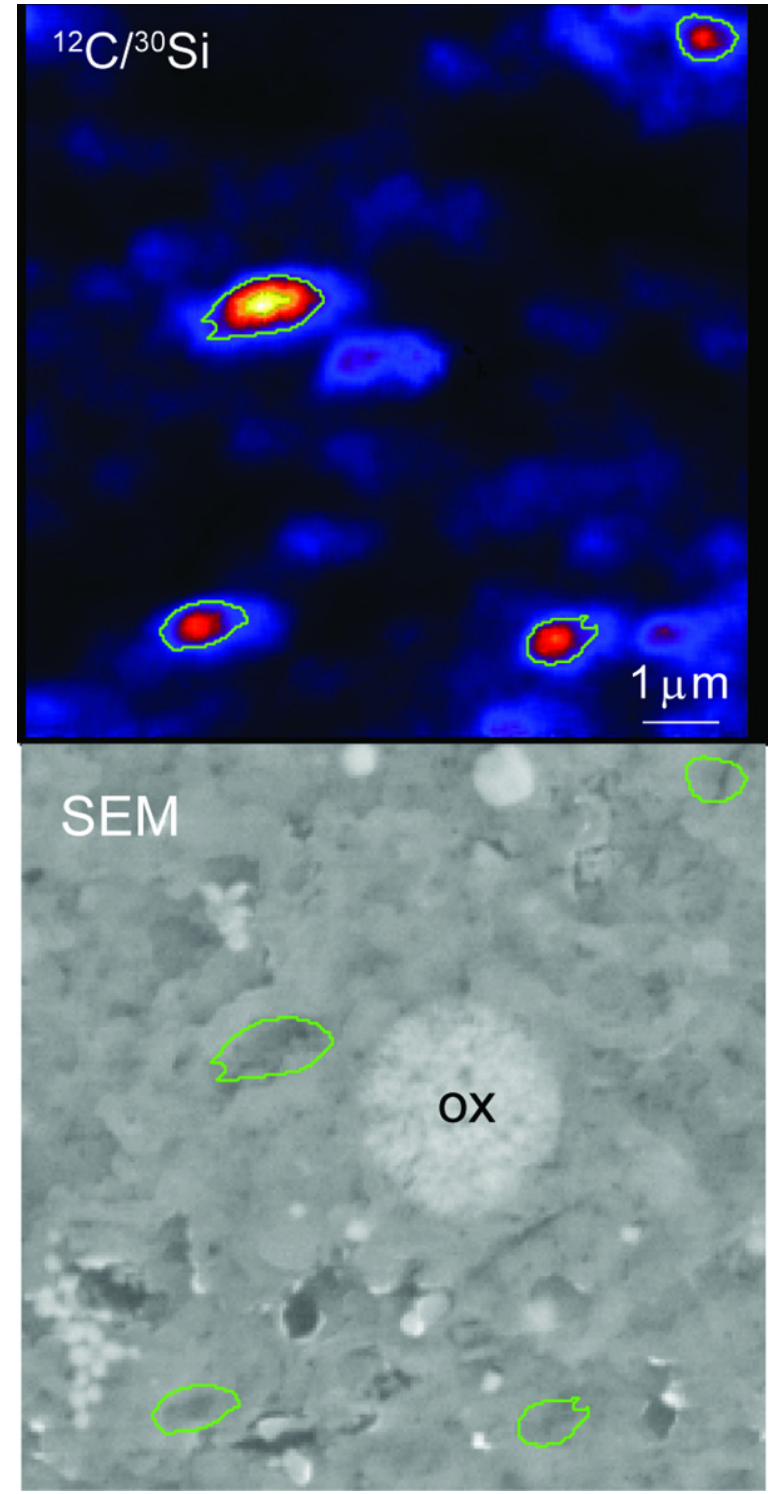

Figure 3. ${ }^{12} \mathrm{C} /{ }^{28} \mathrm{Si}$ ratio images and corresponding SEM image (backsquattered electrons) of a $10 \times 10 \mu \mathrm{m}^{2}$ area in Orgueil. This area is the same as reported in Figure 1. This image clearly shows that the organic particles are not associated with any mineral. The oxide grain (ox) does not have any organic coating around it. Moreover, the D-rich hot spot does not have any inorganic neighbor that can explain the isotopic difference with the other organic particles. The different isotopic behavior can then be explained only by an internal property of the organic matter that constitutes the D-rich hot spot.

1973). As confirmed by ${ }^{32} \mathrm{~S} /{ }^{28} \mathrm{Si}$ and ${ }^{18} \mathrm{O} /{ }^{28} \mathrm{Si}$ ratio images (not shown), the D-rich hot spots are not associated with oxides, sulfides or sulfates. There are no recognizable rims or coatings around the organic D-rich particles, ruling out a physical barrier to the isotopic exchange of the deuterium from those particles to the matrix. The D-poor hydrous minerals seem to be in direct contact with the enriched-rich organic matter of the D-rich hot spots. Moreover, all the organic particles (D-rich or not) exhibit the similar lack of association with specific inorganic components (other than hydrous minerals, which are abundant and so adjacent to all minor matrix components). These observations are also true for matrix fragments of Renazzo (not shown). Thus, a general result of our study is that diverse chondrites that appear to vary markedly in extents and conditions of parent-body alteration processes contain similar distributions 


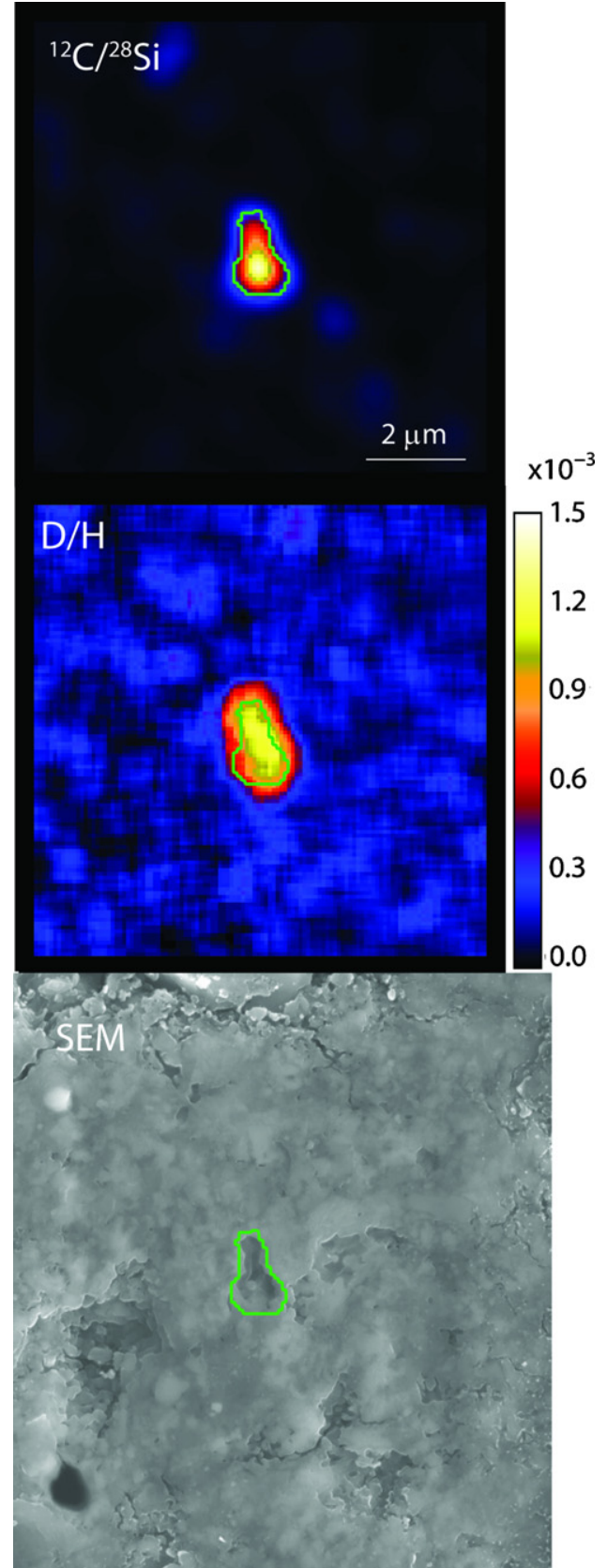

Figure 4. ${ }^{12} \mathrm{C} /{ }^{28} \mathrm{Si}$ and $\mathrm{D} / \mathrm{H}$ images of a $10 \times 10 \mu \mathrm{m}^{2}$ area in Murchison. The SEM (backsquattered electrons) image of the same area is also reported. As for Orgueil, the preservation of the D-rich hot spot does not involve any association with any mineral. The organic D-rich grain is embedded in Fe- and Mg-rich clay minerals, whose composition is close to that measured in the bulk matrix. Note that the shape of the organic particle in the ${ }^{12} \mathrm{C} /{ }^{28} \mathrm{Si}$ image matches a hole in the SEM image; this is likely the result of a faster sputtering of organic material relative to clay minerals.

of C-rich, sometimes D-rich, particles that exhibit no obvious textural, mineralogical, chemical, or isotopic connection to immediately adjacent matrix components. This result suggests that a broadly similar group of C-rich particles was widely sampled during accretion of the parent bodies of diverse chondrites and were largely inert to post-accretionary processes on those bodies.

In summary, there are two main consequences of our observations. One, the isotopic exchange between organic matter and inorganic constituents of the parent bodies of the carbonaceous chondrites was limited, and another, the carbonaceous chondrites accreted two different kinds of organic matter-one rich in $\mathrm{D}$ and the other poor in D but otherwise similar - that have experienced different pre-accretionary conditions. The later point is discussed in Section 5.

\section{DISCUSSION}

The observation of extremely D-enriched organic particles in the carbonaceous chondrites is intriguing. Indeed, organic matter exchanges its D with water and hydrous minerals in the timescale of hundreds of thousands years (Sessions et al. 2004) in sedimentary basins, at temperature around $200^{\circ} \mathrm{C}$. In carbonaceous chondrites, organic matter and clay minerals are associated since the accretion of the parent body and then have evolved for 4.5 billion years. The temperature for most of the history of the parent bodies has remained low (below $0^{\circ} \mathrm{C}$ ), except for a few million years just after the formation of the parent body where it should have reached $20^{\circ} \mathrm{C}-70^{\circ} \mathrm{C}$ during hydrothermal activity on CI and CM parent bodies (Guo \& Eiler 2007).

Several hypotheses can be proposed to account the lack of isotopic exchange between D-rich organic particles and adjacent hydrous phases. (1) Organic matter may be physically isolated from water and hydrous minerals preventing any D loss. (2) The D-rich hot spots actually have exchanged with their surroundings but are rich in organic radicals (Remusat et al. 2009) that may have strongly concentrate $\mathrm{D}$ relative to other phases. Very few data are available about the isotopic behavior of these moieties, and it seems plausible that they could have extreme equilibrium properties. (3) Organic matter may not exchange with the hydrous minerals because water is unavailable or immobile as an exchange medium. Permeability of the organic particles has to be studied to assess this hypothesis. Finally, slow exchange rates at the $\mathrm{P}$ and $\mathrm{T}$ conditions of the parent body may explain our observations (4). This can be assessed by using data obtained from terrestrial organic matter in sediments.

\subsection{Physical Barriers to Isotopic Exchange}

One way to explain the lack of exchange between organic particles and their surroundings is if the organic particles are surrounded by an $\mathrm{H}$-free or non-exchangable impermeable material. For instance, preservation of proteinaceous moieties in refractory organic matter from 140 Ma terrestrial sedimentary rocks has been attributed to that encapsulation in refractory organic matter (Mongenot et al. 2001). Because C-rich particles in the carbonaceous chondrites are relatively homogeneous in the $\mathrm{C} / \mathrm{H}$ ratio, it seems unlikely that they are encased in an impermeable barrier of unusually refractory organic matter. SEM images taken before and after ion imaging do not reveal phases or structures that physically shield the organic particles, and ion images reveal no consistent association of organic particles with any oxide or sulfur-bearing coating. Organic particles appear to be simply embedded in their clay-dominated matrix, with no layer that separates these two components. If such a layer exists, it must be smaller than the scales of our SEM and NanoSIMS images. Transmission electron microscopy imaging may assess if a very thin layer armors the organic particles, but it could not be done in the present study.

\subsection{Isotopic Behavior of Organic Radicals}

Very little is known about the isotopic properties and the isotopic exchange equilibrium constant for the organic 

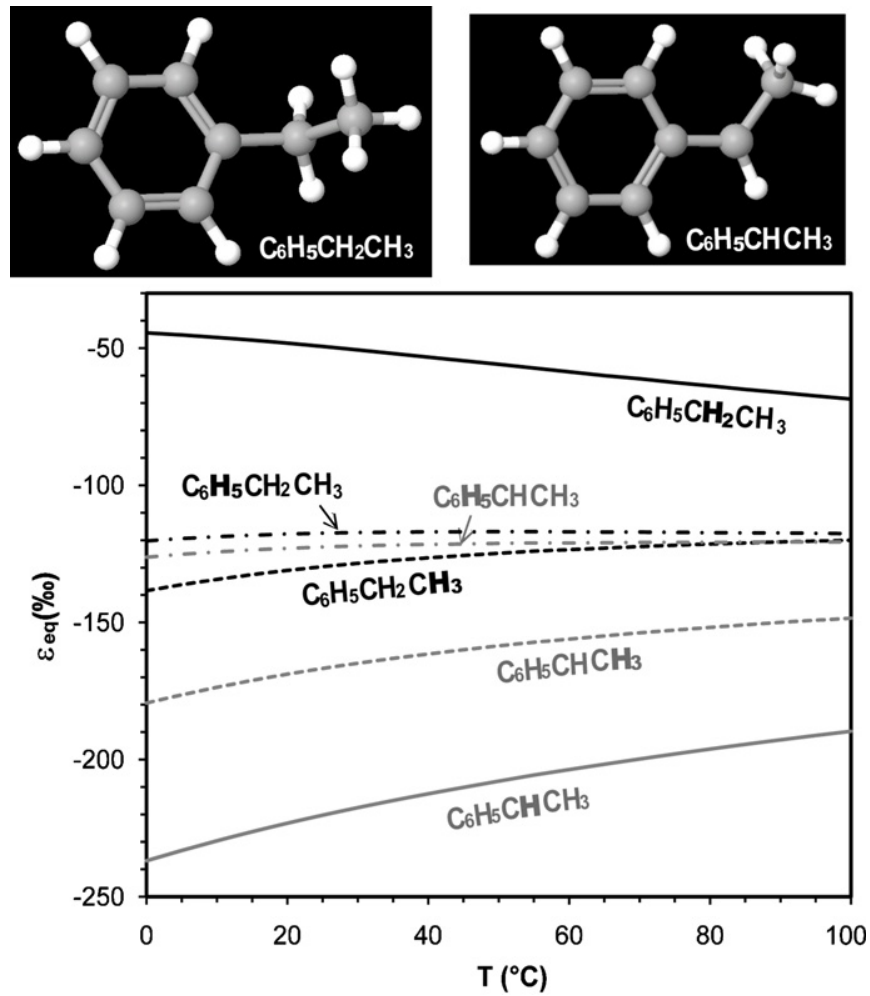

Figure 5. D/H equilibrium fractionations calculated for specific molecular locations in ethylbenzene with and without benzylic radical. The equilibrium value is calculated for each position on the molecules (the position is indicated by the $\mathrm{H}$ in bold). It appears that for all the positions, the organic $\mathrm{H}$ is depleted in $\mathrm{D}$ compared to water. When the molecule contains a radical, the $\mathrm{H}$ bonded to the radical is even more depleted in $\mathrm{D}$ than the other molecular positions.

radicals. It has been recently shown that such species in the IOM of carbonaceous chondrites are extremely D-enriched, with a $\mathrm{D} / \mathrm{H}$ of $1.5( \pm 0.5) \times 10^{-2}$ (Gourier et al. 2008). Moreover, they likely constitute the D-rich component of the D-rich hot spots (Remusat et al. 2009). It is worth considering whether these species are D-rich due to their unusual reduced partition coefficients, and thus might be high in the $\mathrm{D} / \mathrm{H}$ ratio, despite extensive parent-body exchange. To test this hypothesis, we performed ab initio calculations constraining the isotopic equilibrium of organic compounds with water. We have chosen ethyl benzene, a simple molecule that can exhibit a benzylic radical. The results obtained for the ethyl benzene with and without radical are reported in Figure 5.

It appears that all the hydrogen atoms in ethyl benzene are depleted in D compared to water at equilibrium. If a benzylic radical exists, its $\mathrm{D} / \mathrm{H}$ ratio is even lower than the other positions, indicating that the reduced partition coefficients of organic radicals cannot be the cause of elevated $\mathrm{D} / \mathrm{H}$ ratios in $\mathrm{C}$-rich domains of carbonaceous chondites. That is, these firstprinciple models support the common inference that the organic compounds in carbonaceous chondrites are far too rich to be in isotopic equilibrium with parent-body water, regardless of their molecular make-up.

\subsection{Diffusion of Water in the Organic Particles}

It is possible that $\mathrm{C}$-rich particles in carbonaceous chondrites resist $\mathrm{H}$ isotope exchange with their surroundings because they are intrinsically impermeable to water. To our knowledge, no data for diffusion of water in organic particles have been published, but several studies on the diffusion of water through polymers and paints have been reported and may be relevant to the properties of small, kerogenous particles. We consider the case that the diffusivity of water in refractory organic matter is equivalent to that through organic polymers used in food industry, such as PolyEthylene Terephthalate (PET). In amorphous PET, the diffusivity of water $\mathrm{D}$ varies between 0.5 and $8.3 \times 10^{-12} \mathrm{~m}^{2} \mathrm{~s}^{-1}$ for temperatures between $20^{\circ} \mathrm{C}$ and $70^{\circ} \mathrm{C}$ (Launay et al. 1999). The characteristic diffusion timescale, $\tau$, for a particle of dimension 1 can be approximated as $\tau=\mathrm{D} \times 1^{2}$. Assuming a $1 \mu \mathrm{m}$ diameter particle and temperatures within the range of those inferred for parent-body aqueous alteration (Guo $\&$ Eiler 2007), it should take $\sim 1$ s for water to diffuse through a particle. Thus, particles should be fully exposed to water throughout their interiors throughout the duration of aqueous alteration. Thus, impermeability of C-rich particles seems to be an implausible explanation for their lack of $\mathrm{H}$-isotope exchange during parent-body processing.

\subsection{Isotopic Exchange Duration}

Kinetics of the isotopic exchange may also explain the preservation of the deuterium enrichment in the organic particles. As timescale for hydration of the organic particles is very short, the duration of the isotopic exchange at the temperature expected for parent-body hydrothermal alteration may be too long for a significant depletion of the organic matter. We can estimate the duration of exchange of "hot spots" and parent-body water by analogy with the kinetics of hydrogen isotope exchange between water and icosane $\left(\mathrm{a}_{20} \mathrm{H}_{42}\right.$ normal alkane) in the presence of montmorillonite (Sessions et al. 2004). $70 \%$ of the $\mathrm{H}$ in CI and CM IOMs is linked to aliphatic moieties (Cody et al. 2002), so these data should be relevant to our case. At $30^{\circ} \mathrm{C}$, the exchange half-time (i.e., the characteristic time to reduce an isotopic difference, between the $\mathrm{D} / \mathrm{H}$ ratio of a disequilibrated compound and the equilibrated value, to half of its initial value) is $\sim 50,000$ yr. In Orgueil, eight half-times are required to reduce the $\mathrm{D} / \mathrm{H}$ of hot spots to the $\mathrm{D} / \mathrm{H}$ of bulk IOM. This leads to $4 \times 10^{5} \mathrm{yr}$ to destroy the isotopic anomaly in D-rich hot spots. Aléon et al. (2001) have calculated exchange durations for D-depletion of organic matter by exchange with water on parent bodies of interplanetary dust particles (IDPs). They have used results from experimentations on $\mathrm{CH}_{4}$ in the gas phase (Lécluse $\&$ Robert 1994). Nevertheless, if we used the same approach, and by using data from Robert \& Epstein (1982) for water D/H on the parent body, we obtain a shorter duration $(12,800 \mathrm{yr})$ to "erase" the heaviest D-rich hot spot we measured. All of these estimates are several times shorter than the inferred time of water circulation on the parent bodies of carbonaceous chondrites: a few million years based on carbonate formation chronology (Hoppe et al. 2007).

Based on the preceding arguments and calculations, it is difficult to understand how organic particles found in carbonaceous chondrites avoided significant hydrogen isotope exchange with parent-body water. A simple resolution to this dilemma would be that water circulation on these parent bodies was far shorter in duration than suggested by carbonate chronology (Hoppe et al. 2007). Another explanation may come from temperature of the circulating fluid. Indeed, at $7^{\circ} \mathrm{C}$ instead of $30^{\circ} \mathrm{C}$, it takes almost twice the time to equilibrate organic compounds in the same conditions (Sessions et al. 2004). Hoppe et al. have determined their carbonate chronology on Orgueil, and they found that breunnerite was the last formed carbonate. Clumped isotopes indicate a temperature of $-30^{\circ} \mathrm{C}$ for this carbonate in Orgueil (Guo 2009). It has been interpreted as a late brine circulation on Orgueil 
parent body. We may then expect that the temperature decreased quickly and that it got too cold quickly preventing any significant D-exchange between organic matter of the particles and water.

Our result may also point to a discontinuous water circulation on the parent body. If we suppose that water circulation occurred by pulses, then organic matter was not exposed to liquid water during all the period of the hydrothermal alteration. It would have rather been exposed to water during multiple brief events, and each pulse was not long enough to induce significant water diffusion through the particle or isotopic exchange. Moreover, the total exposure time might have been less than a few tenth of thousands years-not enough time for the isotopic exchange to alter the isotopic enrichment of extremely enriched organic particles. This would naturally lead to several episodes of carbonates and other alteration phases in the chondrite. A pulsed water circulation may result from the melting of ice aggregates heterogeneously distributed on the parent body that would release different load of water that could migrate through the cracks in the rocks. Then instead of considering that ices melted at the same time, generating a unique reservoir of water that could then circulate through all the parent body, we may have to consider several reservoirs that release their water at different moments.

However, if we are correct that D-rich IOM has largely escaped hydrogen isotope exchange with parent-body water, some other explanation, such as differences in pre-accretionary history, must be sought for the systematic differences in the $\mathrm{D} / \mathrm{H}$ ratio between $\mathrm{IOM}$ in the $\mathrm{CI}, \mathrm{CM}$, and $\mathrm{CR}$ chondrites (Alexander et al. 2007).

\section{ORIGIN OF ORGANIC PARTICLES ACCRETED IN CI, CM, AND CR PARENT BODIES}

One of the striking observations of this study is that extremely D-rich organic particles are closely associated with moderately D-enriched organic particles in the matrices of CI, CM, and CR chondrites (Figure 1). This difference cannot be attributed to isotopic exchange with laboratory reagents because we have examined untreated matrix samples. Both ion imaging and secondary-electron imaging fail to reveal any differences among these particles in their textural setting (i.e., "armoring" phases), nor in their internal chemical or isotopic zonation. None of these particles also preserve obvious evidence of $\mathrm{H}$ isotope exchange with their surroundings. Thus, it is difficult to imagine how differences in isotopic composition between those two kinds of particles could be explained by parent-body processes. Alexander et al. (2007) have argued that the parent bodies of the carbonaceous chondrites initially accreted with a component of IOM that was uniform in hydrogen isotope composition, and that diversity of bulk isotopic composition of chondritic IOM reflects post-accretionary parent-body processes. Our results and discussion suggest this cannot be true for the component of IOM contained in carbon-rich particles. In fact, we have found the most enriched D-rich "hot spot" in Orgueil, the chondrite having the greatest extent of bulk alteration. This is consistent with the bulk $\mathrm{D} / \mathrm{H}$ ratio in $\mathrm{CI}$ and $\mathrm{CM}$ that show that $\mathrm{CI}$ are not fragments of aqueously altered CM parent bodies (Eiler \& Kitchen 2004). Moreover, Eiler and Kitchen have shown that the volatile content in the CM does not fit a model of the formation of $\mathrm{CI}$ chondrites by the hydrothermal alteration of a CM precursor. Then, D/H trends in both organics and bulk rock in CI and CM are explained by different sources rather than aqueous alteration on the parent body.
Indeed, if parent-body processes do not explain the difference in hydrogen isotope composition among the carbon-rich particles, then they must have accreted as a collection of isotopically diverse grains. Extreme D enrichments in meteoritic organic matter are generally understood to be consequences of low temperature chemistry in irradiated environments: gas phase ion-molecule reactions, gas grain reactions, gas phase photodissociation or photolysis of ice mantles (Sandford et al. 2001). Thus, a diversity in $\mathrm{D} / \mathrm{H}$ ratios of organic particles could reflect diversity in the environments in which the surfaces or adsorbed components of those particles underwent such chemical reactions, and the presence of diverse particles in a single meteorite would then reflect mixing processes in the nebula that permitted grains that had been processed in different conditions to be accreted together (see Figure 6). It has been shown that the outer part of the early solar system could have been subjected to intense UV irradiation and low temperatures, creating a D-rich ionized molecular hydrogen gas (Ceccarelli \& Dominik 2005). This environment could induce the formation of organic radicals that could undergo rapid hydrogen isotope exchange with the ionized gas, leading to extreme D-enrichments in organic matter in ice mantles or sublimated from organic particles (Remusat et al. 2009). During the era of the solar system history in which these conditions prevail on the outer edge of the nebula, the mid plane of the nebula is characterized by higher temperatures and denser gas, leading to less irradiation; consequentially, organic particles or mantles that condense and grow in these environments should not acquire extreme deuterium enrichments (Remusat et al. 2006). Turbulent radial and vertical transport can result in the mixing of organic particles exposed to the outer regions of the solar system with organic particles from the mid plane (Ciesla 2009). That is, we could think of the multiple kinds of C-rich particles found in the carbonaceous chondrites as analogous to CAI-like material found in comet grains recovered by the stardust mission (Zolensky et al. 2006): organic components and comet grains represent mechanical mixtures of particles that were chemically processed in diverse nebular environments.

It is possible that deuterium-rich particles observed in this study are interstellar grains added to the early solar nebula (Busemann et al. 2006). However, the highest D/H measured in organic particles in carbonaceous chondrites, in this and previous similar studies, are at the lower end of the distribution of $\mathrm{D} / \mathrm{H}$ measured in the interstellar medium $(\mathrm{D} / \mathrm{H}$ ranging from 2000 to $60,000 \times 10^{-6}$; Robert 2002), and we have shown in this study that isotopic exchange is not significant enough to lower an interstellar like $\mathrm{D} / \mathrm{H}$ ratio to a value in the range of chondritic values. Therefore, it is not clear how one would explain the lack of particles in chondrites having $\mathrm{D} / \mathrm{H}$ ratios on the order of $10^{-2}$. We suggest that the D-rich organic particles in chondrites could only be inherited from the interstellar medium, prior to the formation of the protosolar nebula, if there were a process that selectively added only those with the lowest $\mathrm{D} / \mathrm{H}$. We are aware of no such process, and so we prefer the hypothesis that these particles formed in the protosolar nebula.

If the accretion scenario we present above is correct, it leads to two important conclusions. (1) Carbonaceous chondrites did not accrete a single population of organic precursors (at least, with regard to their hydrogen isotope geochemistry); rather, their organic constituents represent a physical mixture that samples diverse nebular environments (or solar and interstellar). It is possible that all organic-rich particles in chondrites are synthesized by a common family of processes (this actually 


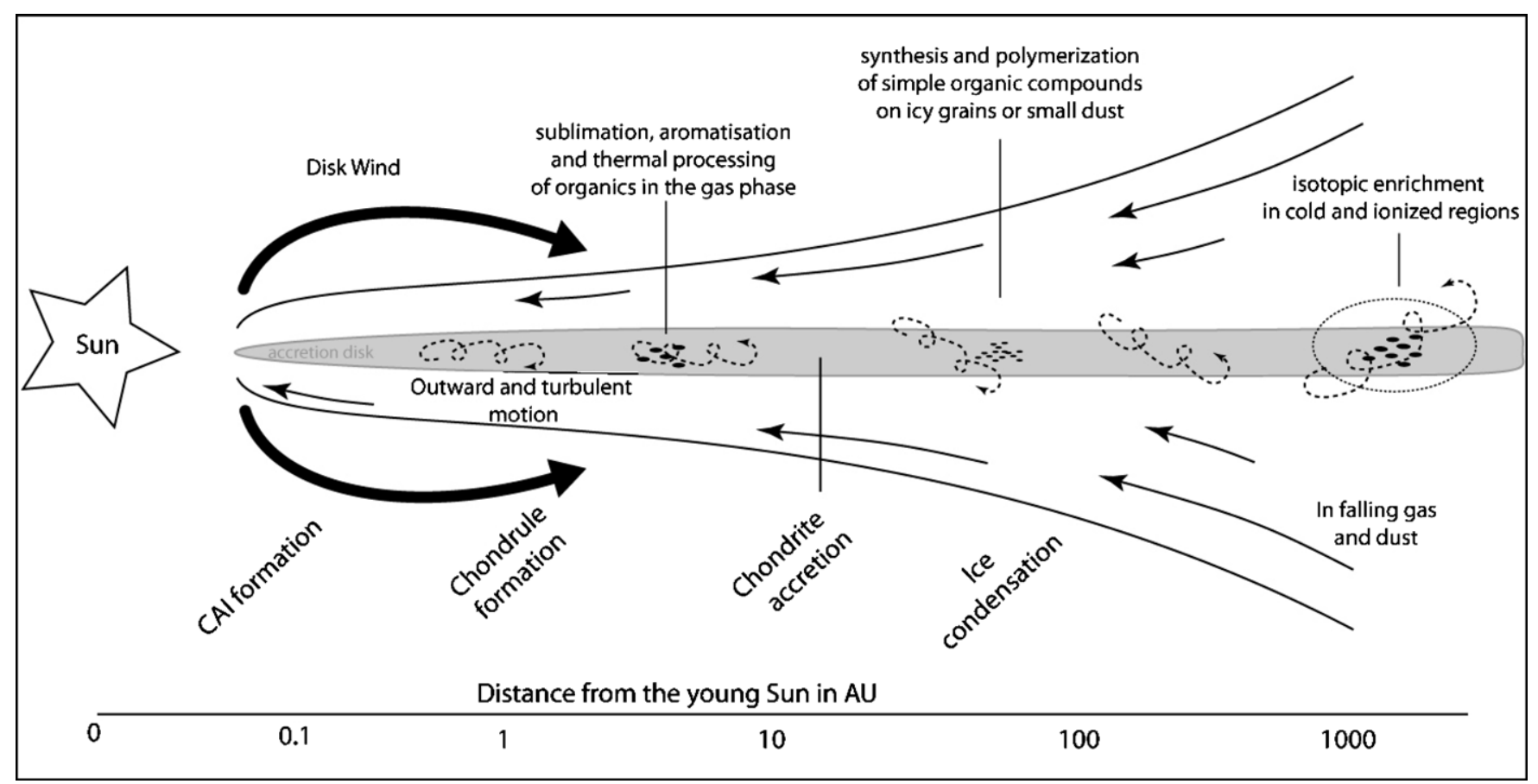

Figure 6. Cartoon of the early solar nebula showing potential locations for the processes that influence the insoluble organic matter evolution and synthesis. These processes occurred in a turbulent nebula where inward gas and particle motion are counterbalance by outward transport in the midplane (accretion disk). Synthesis of large macromolecules likely started in cold areas where simple organic moieties could condense on to icy grains. These icy organic grains could have been exposed to irradiation from the young Sun or the interstellar medium to produce chemical reactions leading to polymerization of the simplest compounds. These particles could be transported to inner or outer regions of the disk. The high temperature would induce sublimation of those molecules and aromatization to produce aromatic units. The outer regions should be characterized by the occurrence of an ionized molecular gas, where the deuterium enrichment could occur. Depending on the time they spend in outer and inner areas, and how far they go, organic particles would acquire different isotopic ratios and molecular structure. Then, those particles would get into the chondrite accretion regions where they would be trapped in parent bodies with inorganic constituents. Then their nebula evolution stops. It must be noted that the nebula is evolving in time, leading to a shift in the distance to the Sun as the time evolved. Figure inspired by Ciesla (2009), Cuzzi et al. (2003), Scott (2007), and Shu et al. (1997), modified.

seems likely to us given how self-similar they are in size and $\mathrm{C} / \mathrm{N} / \mathrm{H}$ stoichiometry). However, the marked diversity in hydrogen isotopic compositions of these particles indicates that those reactions took place in diverse environments-some cold and bathed in UV radiation and with an ionized molecular gas; some warm and isolated from UV photochemistry (see Figure 6). (2) Our images allow us to explain the heterogeneous distribution of organic radicals observed in IOM. Indeed, in IOM, organic radicals are concentrated in radical rich areas (Binet et al. 2002), but the origin of this heterogeneous distribution was not assessed by Binet et al. (2002) and remained an open question. In the bulk meteorites, the D-rich hot spots, which are related to radical-rich organic matter (Remusat et al. 2009), constitutes organic single particles. But during the demineralization process, the silicates are dissolved, and the organic particles are stacked to each other to form grains of IOM, with some refractory inorganic grains. As the organic particles should not disaggregate during the acid treatment, D-rich organic hot spots remain as isolated D-rich and radical-rich grains, making the heterogeneous distribution we observe in IOM. Then $\mathrm{D} / \mathrm{H}$ ratio images of IOM, showing isolated D-hot spots, are the result of the mechanical mixing of two kinds of organic matter, one having an extremely high $\mathrm{D} / \mathrm{H}$ ratio, the other being moderately enriched in $\mathrm{D}$. The only remaining questions to assess are the origin of these radicals and their preservation on the parent-body during the hydrothermal alteration. These questions are also related to the scenario for the isotopic evolution of the organic particles we have proposed earlier. As for the isotopic enrichment, radicals are preserved from hydrothermal alteration by a very short exposure to warm water. Moreover, they can likely form in the same ionized environment expected to induce the high D-enrichment.

\section{CONCLUSION}

In situ observation of organic particles in the matrices of CI, $\mathrm{CM}$, and $\mathrm{CR}$ carbonaceous chondrites reveals the occurrence of two kinds of organic particles. Some exhibit $\mathrm{D} / \mathrm{H}$ ratios in the range of bulk IOM previously reported, the others are extremely enriched in deuterium, with isotopic ratios consistent with D-rich hot spots observed in IOMs of some carbonaceous chondrites. Organic particles do not exhibit any specific association with any mineral. They are embedded in hydrous silicate minerals that make up the bulk of chondritic matrices.

The heterogeneous distribution of organic radicals in chondritic IOM is a consequence of the accretion, on the parent body of CI, CM, and CR chondrites, of two families of organic particles: some are radical-rich (and then extremely enriched in D) and others, more abundant have much less radicals. Radical-rich organic particles are less abundant as a consequence of the larger distance to achieve to get from the irradiated area, where they have been exposed to deuterated ionized gas, to the chondrite accretion area. Moreover, this irradiated area constitutes a small volume of the nebula. Chemical treatment to concentrate IOM does not homogenize the IOM of these particles, leaving D-rich organic hot spots embedded in IOM. 
Isotopic profiles through D-rich organic hot spots indicate that little or no isotopic diffusion has occurred between organic matter and inorganic constituents. This is likely the result of a low temperature for most of the history of the parent body, and only brief $\left(10^{5} \mathrm{yr}\right.$ or less $)$ periods of elevated temperatures during aqueous alteration events. This implies that carbonaceous chondrites have accreted organic matter from various origins in the protosolar nebula, ruling out the occurrence of a common organic precursor. These observations are consistent with the occurrence of vertical and radial transport in the early solar system, which could cause organic matter with different isotopic signatures, generated in different parts of the nebula, to coaccrete (Figure 6). The D-rich organic hot spots have been exposed to the outer regions of the early solar system, where they have undergone radical formation and isotopic exchange.

François Robert and Weifu Guo are thanked for providing samples. We also thank Alex Session for helpful discussions. L.R. is grateful to Nivedita Thiagarajan for her useful comments on the manuscript and illustrations. This paper was improved thanks to comments from an anonymous referee.

\section{REFERENCES}

Aléon, J., Engrand, C., Robert, F., \& Chaussidon, M. 2001, Geochim. Cosmochim. Acta, 65, 4399

Alexander, C. M. O. D., Fogel, M., Yabuta, H., \& Cody, G. D. 2007, Geochim. Cosmochim. Acta, 71, 4380

Alpern, B., \& Benkheiri, Y. 1973, Earth Planet. Sci. Lett., 19, 422

Anders, E., \& Grevesse, N. 1989, Geochim. Cosmochim. Acta, 53, 197

Bigeleisen, J., \& Mayer, M. G. 1947, J. Chem. Phys., 15, 261

Binet, L., Gourier, D., Derenne, S., \& Robert, F. 2002, Geochim. Cosmochim. Acta, 66, 4177

Bonal, L., Bourot-Denise, M., Quirico, E., Montagnac, G., \& Lewin, E. 2007, Geochim. Cosmochim. Acta, 71, 1605

Bonal, L., Quirico, E., Bourot-Denise, M., \& Montagnac, G. 2006, Geochim. Cosmochim. Acta, 70, 1849

Busemann, H., Young, A. F., Alexander, C. M. O. D., Hoppe, P., Mukhopadhyay, S., \& Nittler, L. R. 2006, Science, 312, 727

Ceccarelli, C., \& Dominik, C. 2005, A\&A, 440, 583

Ciesla, F. J. 2009, Icarus, 200, 655

Cody, G. D., \& Alexander, C. M. O. D. 2005, Geochim. Cosmochim. Acta, 69, 1085

Cody, G. D., Alexander, C. M. O. D., \& Tera, F. 2002, Geochim. Cosmochim. Acta, 66, 1851

Cody, G. D., et al. 2008, Earth Planet. Sci. Lett., 272, 446

Cuzzi, J. N., Davis, S. S., \& Dobrovolskis, A. R. 2003, Icarus, 166, 385

Eiler, J. M., \& Kitchen, N. 2004, Geochim. Cosmochim. Acta, 68, 1395

Epstein, S., Krishnamurthy, R. V., Cronin, J. R., Pizzarello, S., \& Yuen, G. U. 1987, Nature, 326, 477

Fuchs, L. H., Olsen, E., \& Jensen, K. J. 1973, Smithsonian Contrib. Earth Sci., 10,39

Garvie, L. A. J., \& Buseck, P. R. 2004, Earth Planet. Sci. Lett., 224, 43
Gourier, D., Robert, F., Delpoux, O., Binet, L., Vezin, H., Moissette, A., \& Derenne, S. 2008, Geochim. Cosmochim. Acta, 72, 1914

Greeley, B. 1994, J. Chem. Phys., 101, 4028

Guo, W. 2009, GPS Division (Pasadena, CA: Caltech), 261

Guo, W., \& Eiler, J. M. 2007, Geochim. Cosmochim. Acta, 71, 5565

Halbout, J., Robert, F., \& Javoy, M. 1990, Geochim. Cosmochim. Acta, 54 1453

Hoppe, P., MacDougall, D., \& Lugmair, G., W. 2007, Meteorit. Planet. Sci., 42, 1309

Horita, J., \& Wesolowski, D. J. 1994, Geochim. Cosmochim. Acta, 58, 3425

Huss, G. R., Rubin, A. E., \& Grossman, J. N. 2006, in Meteorites and the Early Solar System II, ed. D. Lauretta \& H. Y. J. J. McSween (Tucson, AZ: Univ. of Arizona Press), 567

Kerridge, J. F. 1976, Earth Planet. Sci. Lett., 29, 194

Kerridge, J. F. 1983, Earth Planet. Sci. Lett., 64, 186

Krot, A. N., Hutcheon, I. D., Brearley, A. J., Pravdivtseva, O. V., Petaev, M. I., \& Hohenberg, C. M. 2006, in Meteorites and the Early Solar System II, ed. D. Lauretta \& H. Y. J. J. McSween (Tucson, AZ: Univ. of Arizona Press), 525

Launay, A., Thominette, F., \& Verdu, J. 1999, J. Appl. Polym. Sci., 73, 1131

Lécluse, C., \& Robert, F. 1994, Geochim. Cosmochim. Acta, 58, 2927

Lodders, K. 2003, ApJ, 591, 1220

Mongenot, T., Riboulleau, A., Garcette-Lepecq, A., Derenne, S., Pouet, Y., Baudin, F., \& Largeau, C. 2001, Org. Geochem., 32, 199

Nakamura, K., Zolensky, M. E., Tomita, S., Nakashima, S., \& Tomeoka, K. 2002, Int. J. Astrobiol., 1, 179

Nakamura-Messenger, K., Messenger, S., Keller, L. P., Clemett, S. J., \& Zolensky, M. E. 2006, Science, 314, 1439

Pearson, V. K., Sephton, M. A., Kearsley, A. T., Bland, P. A., Franchi, I. A., \& Gilmour, I. 2002, Meteorit. Planet. Sci., 37, 1829

Pizzarello, S., Cooper, G. W., \& Flynn, G. J. 2006, in Meteorites and the Early Solar System II, ed. D. Lauretta \& H. Y. J. J. McSween (Tucson, AZ: Univ. of Arizona Press), 625

Pizzarello, S., Krishnamurthy, R. V., Epstein, S., \& Cronin, J. R. 1991, Geochim. Cosmochim. Acta, 55, 905

Remusat, L., Derenne, S., Robert, F., \& Knicker, H. 2005, Geochim. Cosmochim. Acta, 69, 3919

Remusat, L., Le Guillou, C., Rouzaud, J.-N., Binet, L., Robert, F., \& Derenne, S. 2008, Meteorit. Planet. Sci., 43, 1099

Remusat, L., Palhol, F., Robert, F., Derenne, S., \& France-Lanord, C. 2006, Earth Planet. Sci. Lett., 243, 15

Remusat, L., et al. 2009, ApJ, 698, 2087

Robert, F. 2002, Planet. Space Sci., 50, 1227

Robert, F., \& Epstein, S. 1982, Geochim. Cosmochim. Acta, 46, 81

Sandford, S., Bernstein, M. P., \& Dworkin, J. P. 2001, Meteorit. Planet. Sci., 36 , 1117

Scott, E. R. D. 2007, Ann. Rev. Earth Planet. Sci., 35, 577

Scott, E. R. D., \& Krot, A. N. 2003, in Treatise of Geochemistry, ed. A. M. Davis (Oxford: Elsevier), 144

Sephton, M. A., Verchovsky, A. B., Bland, P. A., Gilmour, I., Grady, M. M., \& Wright, I. P. 2003, Geochim. Cosmochim. Acta, 67, 2093

Sessions, A. L., Sylva, S. P., Summons, R. E., \& Hayes, J. M. 2004, Geochim Cosmochim. Acta, 68, 1545

Shu, F. H., Shang, H., Glassgold, A. E., \& Lee, T. 1997, Science, 277, 1475

Urey, H. C. 1947, J. Chem. Soc., 562

Yabuta, H., Naraoka, H., Sakanishi, K., \& Kawashima, H. 2005, Meteorit. Planet. Sci., 40, 779

Yang, J., \& Epstein, S. 1983, Geochim. Cosmochim. Acta, 47, 2199

Zolensky, M. E., et al. 2006, Science, 314, 1735 